\title{
EVALUATION OF MACHINING FORCES AND SURFACE INTEGRITY ON AISI 304 STEEL TOP MILLING PROCESS UNDER DIFFERENT CUTTING CONDITIONS
}

\author{
Rafael da Cunha Hamano ${ }^{1}$, Hector Reynaldo Meneses Costa ${ }^{2}$ and Tatiane de Campos Chuvas ${ }^{3}$
}

${ }^{1,2,3}$ Federal Center for Technological Education Celso Suckow da Fonseca - CEFET. Rio de Janeiro, Brasil.

Email: rafaelhamano@gmail.com, hectorey@gmail.com, tatiane.chuvas@cefet-rj.br

Received: Oct 29th, 2019

Accepted: Oct 31 th, 2019

Published: December 02 ${ }^{\text {th }}, 2019$

Copyright (C2016 by authors and Galileo Institute of Technology and Education of the Amazon (ITEGAM).

This work is licensed under the Creative Commons Attribution International License (CC BY 4.0). https://creativecommons.org/licen ses/by/4.0/

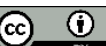

Open Aceess

\begin{abstract}
Stainless steels are widely applied in corrosive environments requiring high mechanical strength. Thus, this material is applicable to the petroleum, gas and petrochemical industries in general. Because they are widely used, it is important to work these materials in a different manufacturing process, in order to reach the desired shapes and dimensions for parts and components. With regard to the behavior of this class of materials when subjected to machining processes, they are defined as low machinability and due to this characteristics, it becomes essential to determine machining forces evaluated in each process, since they define the power required for machines. In addition, it is possible to optimize cutting parameters in order to increase tool life and /or improve surface quality of the machined parts based on the cutting forces. Therefore, the purpose of this work is to analyze how different cutting parameters (cutting speed and feed per tooth), lubrication condition and tool wear might affect machining forces and surface roughness of the AISI 304 in top milling operations. The results demonstrate that the feed per tooth has a greater impact on the increase of the machining forces. In terms of lubrication, Minimum Quantity Lubrication (MQL) has shown to be the best choice upon the dry machining setup, since lower milling forces have been acquired and tool life has been expanded.
\end{abstract}

Keywords: Milling; Tool Wear; Stainless steel; Machining Forces; Surface Integrity.

\section{INTRODUTION}

Stainless steels have great applicability in the aeronautics, aerospace, biomedical, and mechanical industries in general. Thus, this material is widely applied under conditions requiring high mechanical strength and corrosion resistance [1]. Nevertheless, this class of material is characterized by low machinability compared to common carbon steels. Among the difficulties in machining, it can be pointed out the high rate of hardening and long chips, which accentuate tool wear [2]. Machining processes are of great importance in the industry because it is a relatively simple and versatile operation. However, in order to reach optimized cutting parameters, it is necessary to know the process variables well. The challenge is to achieve good dimensional tolerances, finish and cost reduction, according to the different combinations for the process input. Given this, the machining forces is a matter of great relevance for the industry because, in certain circumstances, machining forces define feasibility of the machining process. Many cutting parameters can influence on the cutting forces. According to [3], these forces are mainly affected by the increase of the cutting speed because the heat generated makes the material softer at the shear zone. As a consequence, lower cutting force is required for machining operations which decreases the surface roughness. Cutting forces likewise decrease at higher cutting speed due to the reduction of chip thickness resulting in lower surface roughness. [4], point out from their experiment that feed rate has a greater influence on the values for the surface roughness than the cutting speed. Another element that has great impact on the cutting forces is tool wear, which may intensify the cutting forces as tool wear progresses.

According to [5], cutting fluids (CFs) have major contribution to final product quality and tool life, as they lubricate the cutting zone and flush ships away. Nevertheless, today's manufacturing industries are paying attention to negative impacts over social, health and economic picture of society caused by machining processes, forcing industries to moderate the use of CFs. 
In some machining processes, it is mandatory to use CFs, due to the amount of heat generated. Thus, Minimum Quantity Lubrication (MQL) is an alternative for cooling, flushing and lubricating, and also reducing costs associated with coolants.

[6] describe stainless steel as a material that is typically difficult to machine. This material is also described as having high tenacity and thermal intensity, which results in severe work hardening and heat. As consequence, built-up edges (BUE) are easily produced. On the other hand, conventional coolant method based on flooding system might be ineffective as the coolant often fails to penetrate into the chip interface during the machining process. That leads researches to investigate the process of machining Stainless Steel 304 under MQL. [7], point out that MQL techniques has shown superior quality over wet and dry milling in terms of tool wear on stainless steel 304.

Hence, the current work evaluates how the cutting parameters, lubrication condition and tool wear can influence the machining forces and their impact on the surface integrity of AISI 304 austenitic stainless-steel workpieces machined by top milling method.

\section{EXPERIMENTAL PROCEDURE}

The material analyzed in this study was a rectangular plate made of AISI 304 stainless steel. Figure 1 illustrates the workpiece with a canal on the longitudinal direction, indicating the path applied to the milling process.

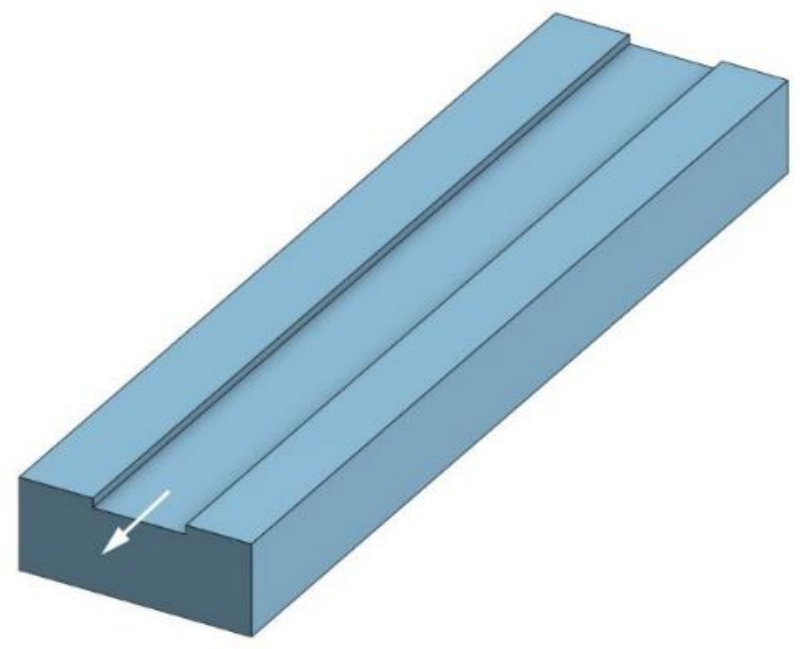

Figure 1: Workpiece illustration. Source: Authors, (2019).

In this work two cutting parameters have been evaluated: cutting speed $\left(v_{c}\right)$ and feed per tooth $\left(f_{z}\right)$ under two cutting fluid application conditions: dry and MQL, totaling 8 conditions, as represented Table 1. The samples were machined through the top milling process, using a $20 \mathrm{~mm}$ diameter mill with two inserts, which with two cutting edges. The inserts applied to the current milling are R390-11T3 08M-PM, class 4240. Cutting speeds were set at the lower and upper limits of the cutting tool manufacturer's recommendations. Depth of cut remained constant at $0,2 \mathrm{~mm}$ per pass. Machining forces measurements were analyzed using a dynamometer manufactured by Kistler Instrument AG, Model 30 9257 BA, coupled to the Diplomat 3001 milling machine. The acquisition rate was at $1 \mathrm{khz}$ and simultaneously measuring 3 orthogonal force components $\left(F_{x}, F_{y}\right.$ e $\left.F_{z}\right)$ through piezoelectric crystal plates, as observed in Figure 2.
Table 1: Cutting parameters and their conditions for milling studies.

\begin{tabular}{|c|c|c|c|}
\hline Condition & $\begin{array}{c}\text { Fluid } \\
\text { Application } \\
\text { Condition }\end{array}$ & $v_{c}[\mathrm{~m} / \mathrm{min}]$ & $f_{z}[\mathrm{~mm} /$ tooth $]$ \\
\hline 1 & \multirow{4}{*}{ Dry } & \multirow{2}{*}{210} & 0,080 \\
\hline 2 & & & 0,135 \\
\hline 3 & & \multirow{2}{*}{225} & 0,080 \\
\hline 4 & & & 0,135 \\
\hline 5 & \multirow{4}{*}{ MQL } & \multirow{2}{*}{210} & 0,080 \\
\hline 6 & & & 0,135 \\
\hline 7 & & \multirow{2}{*}{225} & 0,080 \\
\hline 8 & & & 0,135 \\
\hline
\end{tabular}

Source: Authors, (2019).

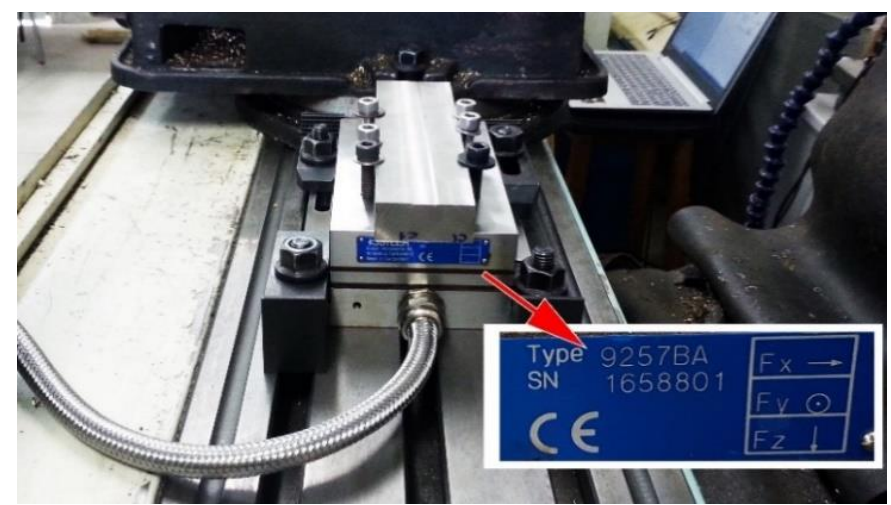

Figure 2: Dynamometer tag indicating Fx, Fy and Fz axes orientation.

Source: Authors, (2019).

Tool wear analysis were performed on the Olympus BX60M optical microscope from Laboratório de Materiais (LAMAT) located at CEFET / RJ. Flank wear were measured as a function of the machining length $\left(L_{f}\right)$ under cutting parameters.

\section{RESULTS AND DISCUSSION}

Figure 3 indicates how Flank Wear measurements develop for Dry and MQL machining under different cutting parameters. In this circumstance, it is possible to assume that MQL has performed better to this class of material in terms of tool wear, as machining forces were lower in all parameters combination, in accordance to [7]. On the other hand, dry machining reveals an accelerated tool wear increase. Even though flank wear can be observed for all conditions, BUE has also been found mostly for dry machining at higher feed per tooth rates as a consequence of higher temperatures. Flank wear analysis demonstrate that the combination of the lowest cutting speed and highest feed per tooth are the best parameters set for both dry and MQL machining, as expected [7]. Lower cutting speeds tend to generate lower temperatures on the cutting zone, as higher cutting speed intensify frictional heat produced by the bottom of chip and at tool rake [8]. Therefore, the cutting temperature increases according to cutting speed, which may decrease tool wear. With respect to feed, higher values tend to decrease the time of contact between inserts and the workpiece, minimizing tool wear provided from friction. In this work the analysis is being made in relation to the machined length $\left(l_{f}\right)$. However, for higher feed conditions, shorter machining time is required. Tools may have the same life span, but at higher feed values, tools will remove more material, making them more economically attractive machining conditions. 

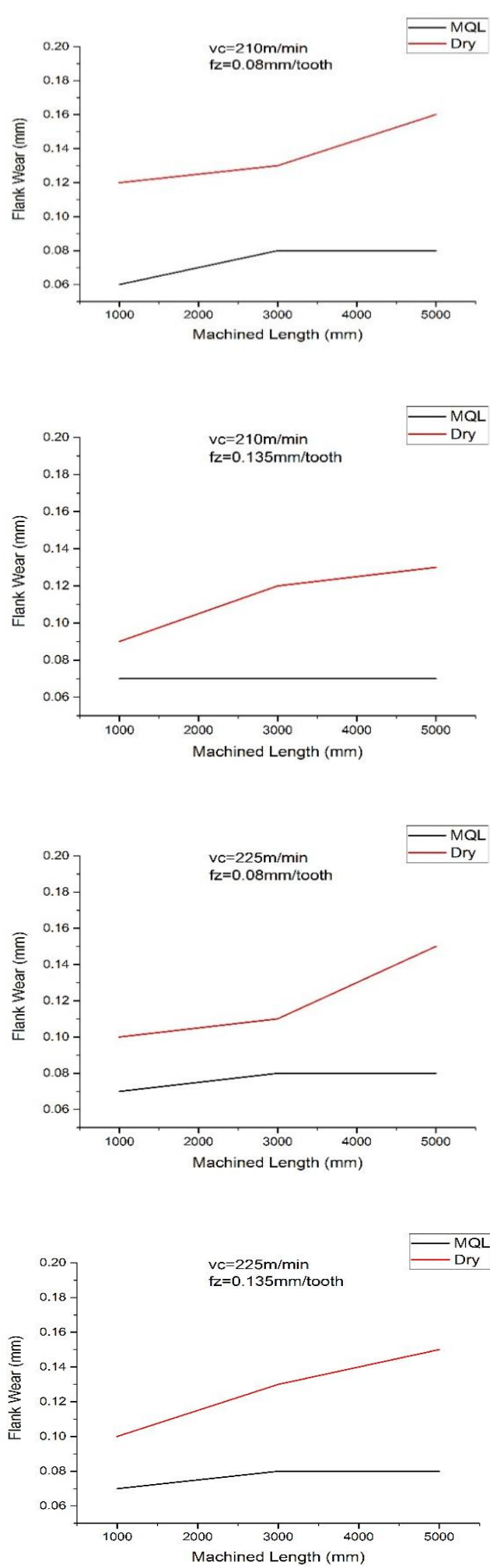

Figure 3: Flank Wear under different machining conditions. Source: Authors, (2019).

A microscopic analysis has been performed to evaluate tool wear under different cutting speed and feed per tooth rates. Figure 4 demonstrates that Flank Wear can be observed for all conditions in dry machining at $l_{f}=5000 \mathrm{~mm}$. Furthermore, it shows that higher feed per tooth resulted in BUE, shown in Fig. $4 \mathrm{~b}$ and 4d. The results are in agreement to [6], who also machined stainless steel in their research and stated that adhesive wear was found on their tools.

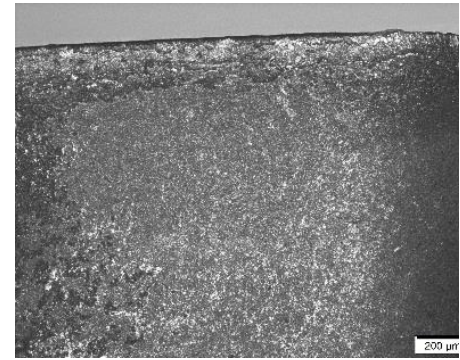

(a) $v_{c}=210 \mathrm{~m} / \mathrm{min} f_{z}=$ $0,08 \mathrm{~mm} /$ tooth

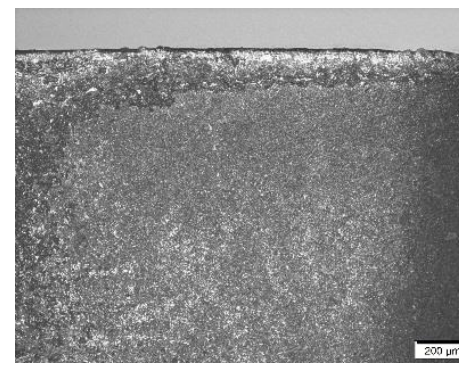

(c) $v_{c}=225 \mathrm{~m} / \mathrm{min} f_{z}=$ $0,08 \mathrm{~mm} /$ tooth

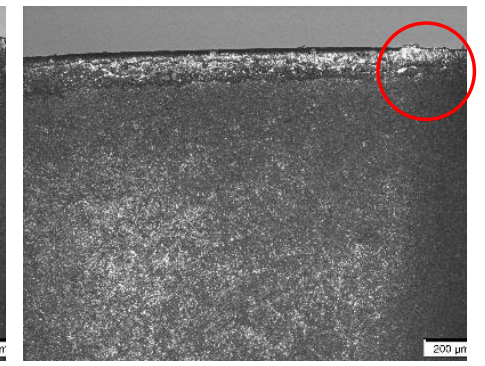

(b) $v_{c}=210 \mathrm{~m} / \mathrm{min} f_{z}=$ $0,135 \mathrm{~mm} /$ tooth

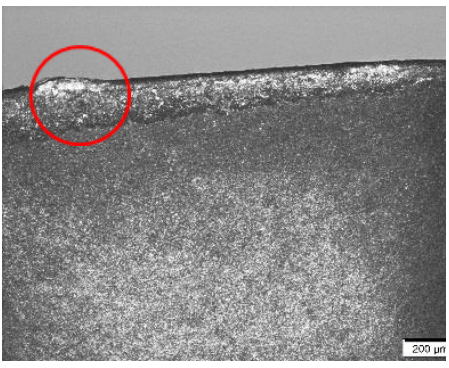

(d) $v_{c}=225 \mathrm{~m} / \mathrm{min} f_{z}=$ $0,135 \mathrm{~mm} /$ tooth
Figure 4: Flank wear under dry machining at $l_{f}=5000 \mathrm{~mm}$. Source: Authors, (2019).

Figure 5 demonstrates the same evaluation on the microscope as the ones observed in Fig. 4, but the inserts were used for milling under MQL conditions. From the analysis, flank wear is much less evident in MQL machining, indicating that MQL has performed better in terms of tool wear.

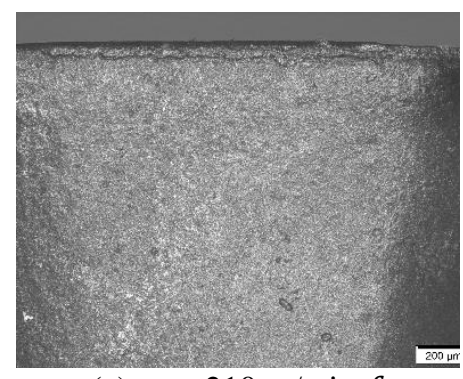

(a) $v_{c}=210 \mathrm{~m} / \mathrm{min} f_{z}=$ $0,08 \mathrm{~mm} /$ tooth

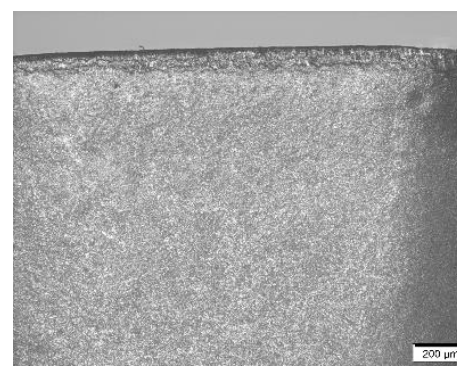

(c) $v_{c}=225 \mathrm{~m} / \mathrm{min} f_{z}=$ $0,08 \mathrm{~mm} /$ tooth

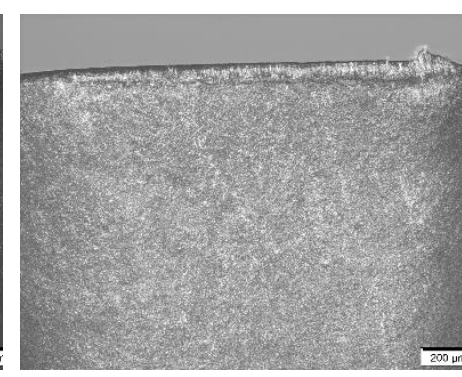

(b) $v_{c}=210 \mathrm{~m} / \mathrm{min} f_{z}=$ $0,135 \mathrm{~mm} /$ tooth

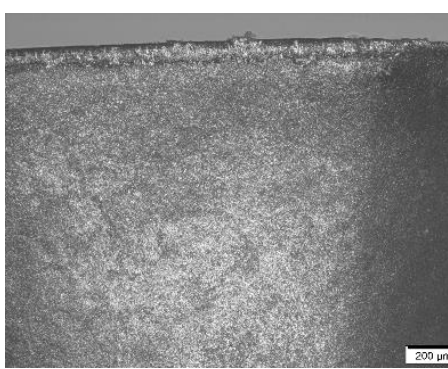

(d) $v_{c}=225 \mathrm{~m} / \mathrm{min} f_{z}=$ $0,135 \mathrm{~mm} /$ tooth
Figure 5: Flank wear under MQL at $l_{f}=5000 \mathrm{~mm}$. Source: Authors, (2019).

In order to compare machining forces generated from different cutting parameters, the resultant force applied to the dynamometer was acquired. Figure 6 reveals data collected from each parameter combination considered in dry condition. Figure 
8a indicates machining forces acquired for $l_{f}=1000 \mathrm{~mm}$ on the workpiece, assuming least tool wear. It can be perceived that machining forces have had their highest averages as the feed per tooth increased, due to the higher removal material rates. Even though it is expected that tool wear would be more pronounced at higher feed per tooth conditions, the opposite effect was revealed. As shown in Figure 3, for the higher feed per tooth, lower flank wear values were observed. What may have occurred is that for low feed rates there is a longer contact time between the inserts and the workpiece, which may accelerate tool wear, especially due to higher temperatures reached during the cutting process. In the matter of cutting speed, there has been no significant variation for machining forces within the ranges of cutting speed analyzed. While Fig. $6 \mathrm{~b}$ illustrates the same research on machining forces, but was measuring values after machined length $l_{f}=5000 \mathrm{~mm}$ on the workpieces was reached. Since cutting parameters were the same for $6 a$ and $6 b$, it is conceivable that machining forces were amplified because of tool wear, which was the only alteration between these two experiments. [9] studied the relationship between cutting forces and tool wear and concluded that cutting forces variations increase during machining because cutting edges gradually lose their effectiveness and become dull. The authors also note that it is possible to estimate pretty accurately tool condition based on cutting forces as long as identical cutting conditions are being compared.

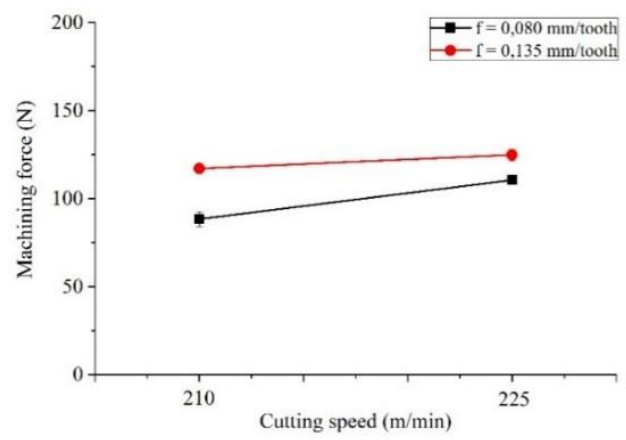

(a) $l_{f}=1000 \mathrm{~mm}$

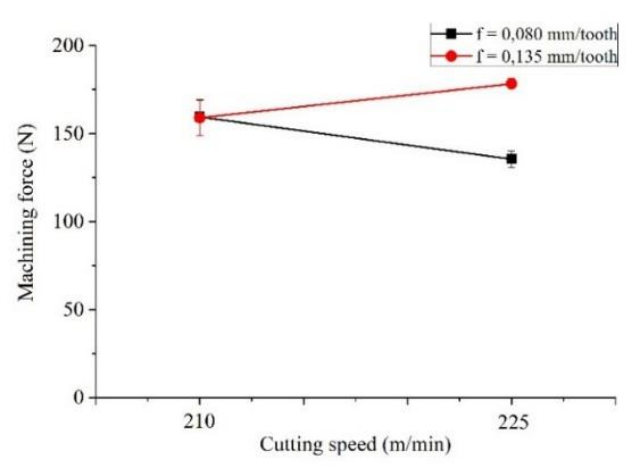

(b) $l_{f}=5000 \mathrm{~mm}$

Figure 6: Machining Forces evaluated at different machined length in dry machining.

Source: Authors, (2019).

Unlike in dry machining, MQL shows a trend on machining force values. The higher the feed per tooth and cutting speeds values, the higher the machining forces are. Figure $7 \mathrm{a}$ illustrates the results acquired for milling under MQL condition over $l_{f}=1000 \mathrm{~mm}$, while Fig. $7 \mathrm{~b}$ displays acquired forces for $l_{f}=5000 \mathrm{~mm}$. A significant advantage of machining under MQL can be perceived from Fig. 7b, which indicates lower machining forces in comparison the ones found in Fig. 6b. These results are directly related to tool wear levels observed in dry machining conditions. Because as flank wear increases, the friction component increases as well, which may also lead to higher machining forces.

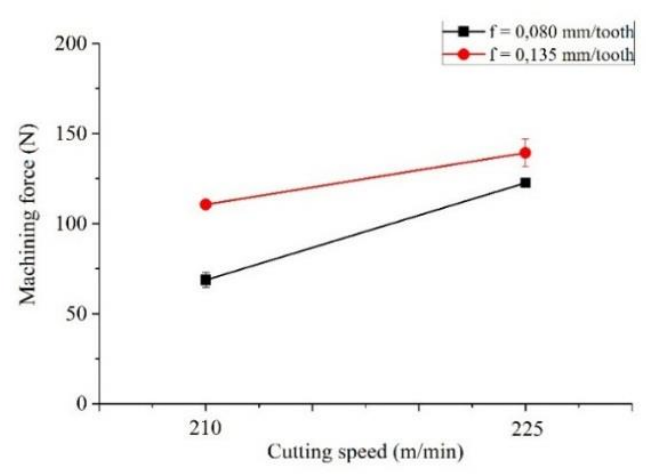

(a) $l_{f}=1000 \mathrm{~mm}$

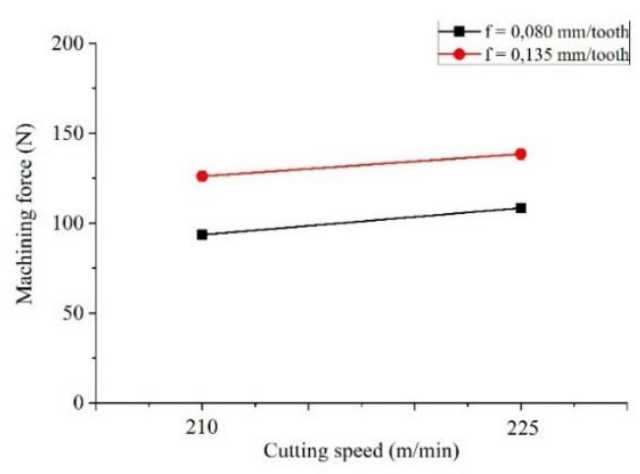

(b) $l_{f}=5000 \mathrm{~mm}$

Figure 7: Machining forces evaluated at different machined length in MQL.

Source: Authors, (2019).

Surface roughness on workpieces were evaluated in order to verify a possible correlation between tool wear, machining forces and surface finishing. Figure 8 illustrates Flank Wear and $\mathrm{Ra}$ roughness simultaneously under different cutting parameters for dry machining. Line graphs contrast acquired roughness, considering different parameters setups. For dry machining, the best results for surface finishing occurred with parameters of high cutting speed and low feed per tooth, represented by condition $8 \mathrm{c}$, as expected [10]. However, a sudden climb for the roughness values was observed after $l_{f}=3000 \mathrm{~mm}$ for all conditions examined, possibly influenced by Flank Wear and Built-Up Edge.

[11] indicated that Flank wear can dramatically develop cutting forces and reduce surface finishing. Figure 9 represents Flank wear and $\mathrm{Ra}$ roughness assessment when lubrication is applied as MQL. Charts demonstrates that roughness values are far more refined those obtained in dry machining, as predicted [7]. In fact, cutting fluid applied to machining may result in a useful combination of lubricating and cooling, which tends to flush the cutting zone and lower machining temperature. It may also improve surface quality on the workpieces. As shown in Figure 3, lower cutting tool wear levels were also obtained under MQL machining conditions. Thus, it is evident that the use of MQL generally improves surface integrity based on roughness evaluation. 


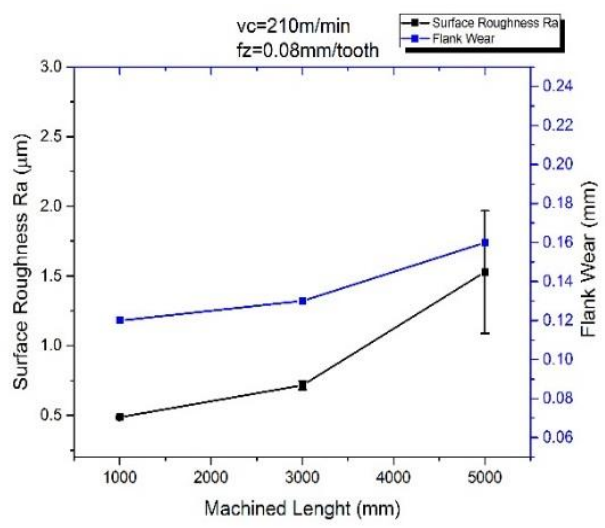

(a) $v_{c}=210 \mathrm{~m} / \mathrm{min} f_{z}=0,08 \mathrm{~mm} /$ tooth

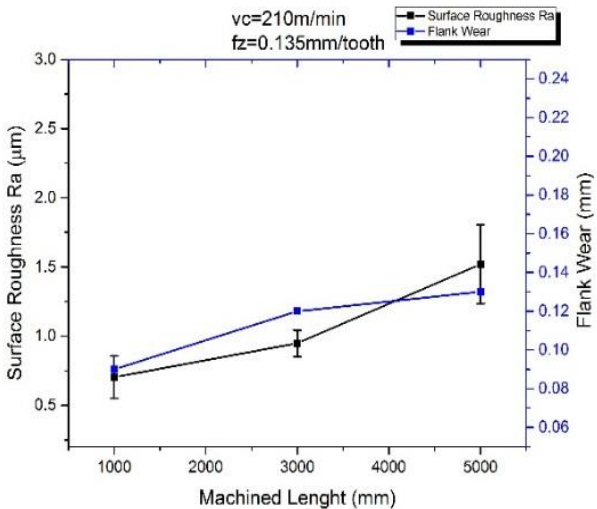

(b) $v_{c}=210 \mathrm{~m} / \mathrm{min} f_{z}=0,135 \mathrm{~mm} /$ tooth

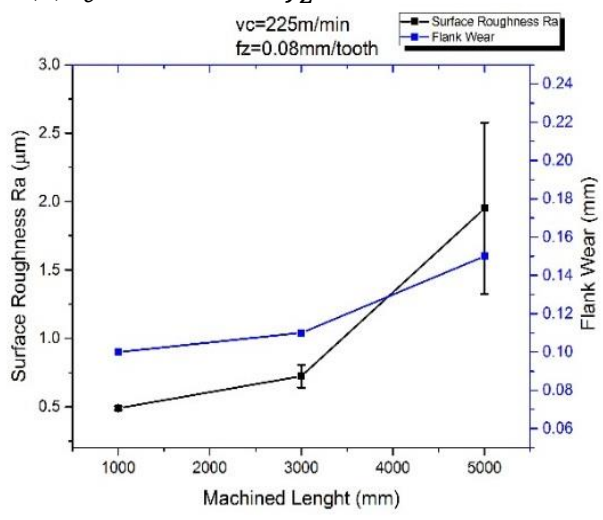

(c) $v_{c}=225 \mathrm{~m} / \mathrm{min} f_{z}=0,08 \mathrm{~mm} /$ tooth

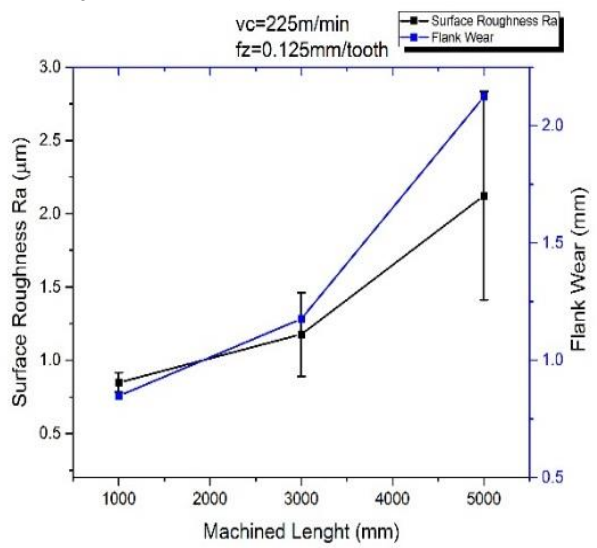

(d) $v_{c}=225 \mathrm{~m} / \mathrm{min} f_{z}=0,135 \mathrm{~mm} /$ tooth

Figure 8: Flank Wear measurements for Dry. Source: Authors, (2019).

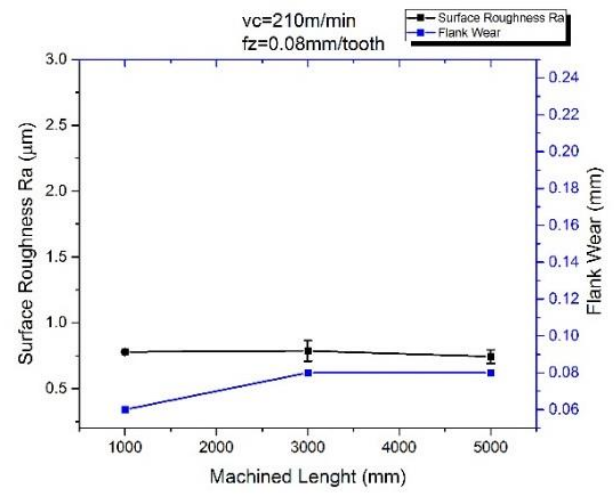

(a) $v_{c}=210 \mathrm{~m} / \mathrm{min} f_{z}=0,08 \mathrm{~mm} /$ tooth

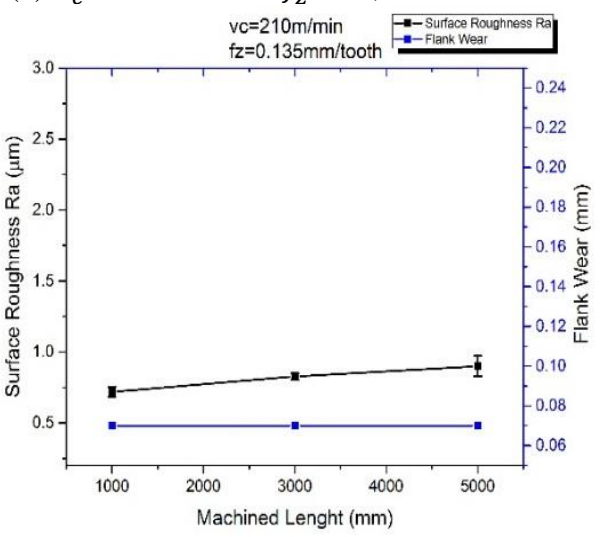

(b) $v_{c}=210 \mathrm{~m} / \mathrm{min} f_{z}=0,135 \mathrm{~mm} /$ tooth

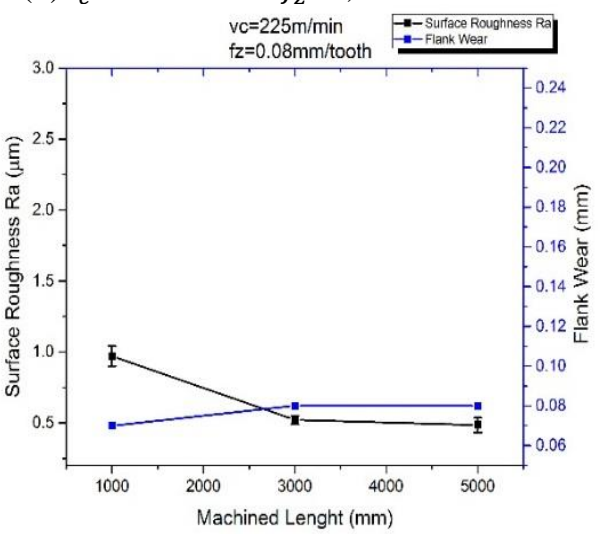

(c) $v_{c}=225 \mathrm{~m} / \mathrm{min} f_{z}=0,08 \mathrm{~mm} /$ tooth

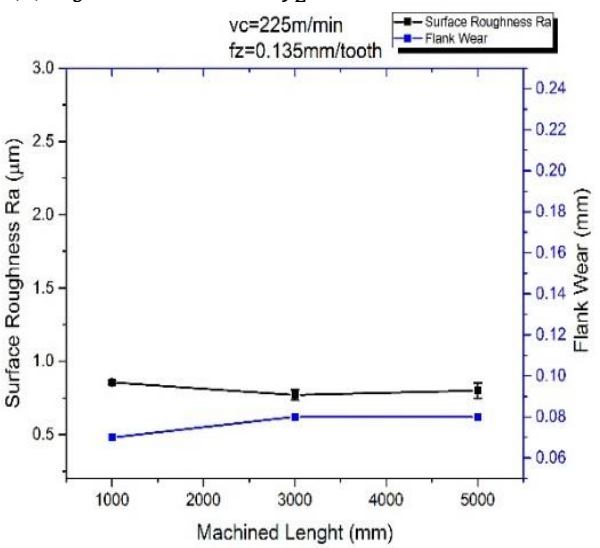

(d) $v_{c}=225 \mathrm{~m} / \mathrm{min} f_{z}=0,135 \mathrm{~mm} /$ tooth

Figure 9: Flank Wear measurements for MQL. Source: Authors, (2019). 


\section{CONCLUSIONS}

Based on the presented results it is possible to conclude that:

1. MQL system provides the best results in terms of tool wear level when machining AISI 304 stainless steel, inhibiting the formation of BUE and extending tool life.

2. The best machining condition, in relation to tool wear level, is corresponding to higher feed per tooth rates, especially for the dry machining.

3. Dry machining resulted in higher machining forces magnitudes, which is directly related to the higher tool wear levels due to higher friction in the cutting process.

4. Overall, MQL is capable of increasing industry productivity by reducing tool replacement and performs better surface quality.

\section{ACKNOWLEDGMENTS}

The authors would like to thank the following institutions for the support given during the execution of the present work: CEFET-RJ, CTEx, CNPq, CAPES and FAPERJ.

\section{REFERENCES}

[1] Tian, M, 2016. "Optimization Method of Process Parameters for Multi-Axis NC Machining of Complex Surface." 6th International Conference on Electronics, Mechanics, Culture and Medicine.

[2] Varghese, V.; chakradhar, D.; Ramesh, M. R. , 2017. Micromechanical characterization and wear performance of TiAlN/NbN PVD coated carbide inserts during End milling of AISI 304 Austenitic Stainless Steel. International Conference on Materials Manufacturing and Modelling. Elsevier.

[3] Selvaraj, D. P., 2019. Experimental Analysis of Surface Roughness of Duplex Stainless Steel in Milling Operation. Advances in Manufacturing Processes, Lecture Notes in Mechanical Engineering. Springer Nature Singapore.

[4]Katta, S.; Chaitanya, G.; Shankar, B. R. , 2019. Optimization Of Tool Wear And Surface Roughness In Turning Titanium (Ti6al-4v) Alloy; Nfmqcf Technique. Journal on Mechanical Engineering.

[5] Dragičević, M. 2018. The Application of Alternative Techniques for Cooling, Flushing and Lubrication to Improve Efficiency of Machining Processes. Faculty of Mechanical Engineering, Computing and Eletrical Engineering. Mostar. Technical Gazette.

[6] Chuangwen, X. et al., 2018. The relationships between cutting parameters, tool wear, cutting force and vibration. Advances in Mechanical Engineering, Gansu, v. 10(1) 1-14.

[7] Singh, S. et al., 2017. Minimum Quantity Lubrication MQL Milling Of Stainless Steel 304 Using Coated Carbide Tool Inserts. I J A M R, Patiala.

[8] He, H.B. et al., 2017. A Study on Major Factors Influencing Dry Cutting Temperature of AISI 304 Stainless Steel. Springer, v. 18, p. 1387-1392. ISSN 2234-7593.
[9] Tansel, I. N. et al., 1999 Tool wear estimation in micromachining Part I: tool usage-cutting force relationship. Elsevier Science, Florida.

[10] Masmiati, N. et al., 2016. Optimization of cutting conditions for minimum residual stress,cutting force and surface roughness in end milling of S50C medium carbon steel. Elsevier.

[11] Zheng, G et al., 2019. Experimental investigation of cutting force, surface roughness and tool wear in high-speed dry milling of AISI 4340 steel. Journal of Mechanical Science and Technology. Springer. 